\title{
AUMENTANDO AS CHANCES DE SUCESSO NO DESENVOLVIMENTO E IMPLEMENTAÇÃO DE SISTEMAS DE INFORMAÇÕES
}

\author{
Alberto Luiz Albertin \\ Professor do Departamento de Informática e Métodos \\ Quantitativos da EAESP/FGV. \\ E-mail: albertin@eaesp.fgvsp.br
}

RESUMO: A implementação de um Sistema de Informaçōes é mais do que simplesmente instalar um sistema desenvolvido e treinar usuários a utilizá-lo. Para que esta implementação tenha sucesso, é necessário, desde o início de seu desenvolvimento até sua efetiva implementação, estudar o contexto no qual ele afuará e formar um ambiente propício para garantir seu desenvolvimento, sua implementação, sua aceitação e uso. O enfoque de variáveis utilizado combina o contexto da organização durante o desenvolvimento e a implementação do $\mathrm{Sl}$, as relaçōes das pessoas que se envolvem com o processo e a estratégia utilizada para garantir o sucesso do projeto.

ABSTRACT: The Information System implementation is more than installing a developed system and training the user to use it. For the implementation success, we need, since its beginning until its implementation, to study the context and build a propitious environment in order to guarantee its development, implementation, acceptance and use. The variables approach combines the organizational context during the SI development and implementation, the relationship among the process participants and the strategy in order to guarantee the project success.

PALAVRAS-CHAVE: sistemas de informações, desenvolvimento de sistemas de informações, implementaçāo de sistemas de informações.

KEYWORDS: information systems, information systems development, information systems implementation. 
1. PORTER, M. E. Estratégia competitiva. São Paulo: Campus, 1986.

2. PORTER, M. E., MILLAR, C $K$. How information gives you competitive advantage. Harvard Business Review, v. 63, n.4, July/August 1985.

3. HENDERSON, J. C. e VENKATRAMAN, N. Strategic Alignment: a model for organizational transformation through Information Technology. In: KOCHAN, T. A. \& USEEM, M. (org.), Transforming Organizations. Oxford: Oxford University Press, 1992.

4. FOGUEL, S. e SOUZA, C. C. Desenvolvimento organizacional. São Paulo: Atlas, 1980.

5. KING, W. R. Strategic planning for management information systems. Management Information Systems Quarterly, v. 2, n. 1, March 1978.

6. McFARLAN, E. W. Information Technology changes the way you compete. Harvard Business Review, v. 62, n. 3 , May/June 1984.
Uma das armas utilizadas para ganhar um avanço competitivo é o uso de Sistema de Informações (SI). Nos últimos anos, encontramos muitos exemplos de organizações que passaram a frente de seus concorrentes por utilizarem melhor a Tecnologia de Informação (TI); ou, por outro lado, de organizações com declínio de ganhos, às vezes à beira da falência, porque seus concorrentes usaram computadores, microeletrônica, redes ou informações em um impulso competitivo.

Segundo Porter ${ }^{1}$, cada empresa que atua em um mercado possui uma estratégia competitiva, seja ela explícita ou implícita. Sendo que, como definido por Porter e Millar², a evolução da utilização da informação está afetando a concorrência em três

\section{A implementação de um SI significa uma mudança, muitas vezes profunda, na organização, que deve ser planejada e preparada para que se garanta seu sucesso.}

meios vitais, citando um deles: "ela cria vantagem competitiva dando às empresas novos meios de superar seus rivais". Hoje, está cada vez mais presente, na preocupação diária dos administradores, a competitividade necessária que uma empresa deve ter para garantir seu sucesso no mercado em que atua, ou pelo menos sobreviver nele.

Henderson e Venkatraman ${ }^{3}$, em seu trabalho sobre alinhamento estratégico entre o negócio da organização e a TI, afirmam que a distância entre a decisão de investir em TI e a realização de retorno enfatiza o risco para as organizações que estão usando TI para iniciar novas estratégias e transformar seus processos de negócio. Portanto, é necessário, cada vez mais, maximizar as chances de sucesso da utilização de SI, ou de TI de uma forma mais ampla.

A implementação de um SI significa uma mudança, muitas vezes profunda, na organização, que deve ser planejada e preparada para que se garanta seu sucesso. A falta de entendimento do processo de intervenção, por parte de expressivo número de líderes organizacionais, tem sido apontada por diversos autores como uma das principais causas de fracassos em tentativas de mudanças em sistemas complexos, conforme mencionado por Foguel e Souza ${ }^{4}$.

Este trabalho visa identificar e enfatizar os pontos relevantes do processo de intervenção nas organizações, quais as principais variáveis, as necessidades de estudálas e a criação de um ambiente propício para o seu sucesso.

\section{A IMPLEMENTAÇÃO DE SI E A ORGANIZAÇÃO}

King ${ }^{5}$ define que o conjunto de estratégias para SI emana diretamente de outro conjunto de informações: o conjunto de estratégias da organização.

A implementação de um SI deve estar de acordo com a estratégia de uso da tecnologia de informação da organização, que, por sua vez, deve ser coerente com a sua estratégia de negócio. Este alinhamento é que deve garantir a alocação de recursos para os projetos de TI e dar as diretrizes para o seu planejamento e suas prioridades.

Para garantir este alinhamento, é imprescindível que os responsáveis pela formulação das estratégias de negócio e a alta gerência tenham conhecimento da potencialidade da utilização de TI e que sejam bem assessorados sobre as oportunidades que ela pode gerar. Por outro lado, os responsáveis pela formulação das estratégias de uso de tecnologia de informação e sua gerência têm que ter bom conhecimento do negócio da organização.

A importância da TI na estratégia de negócio foi enfatizada por McFarlan ${ }^{6}$ ao definir que, em muitos casos, a nova tecnologia tem propiciado uma ótima oportunidade para a organização encontrar uma melhor utilização de seus ativos e repensar sua estratégia, além de ser determinante na sua estratégia competitiva.

Um SI implementado e utilizado numa organização enquadra-se num determinado contexto organizacional, no qual está 
incluída a cultura organizacional, que pode ser definida como aquilo que se sente em toda sua instalação, nas pessoas em que nela trabalham, algo que faz a organização funcionar (mal ou bem) e que está impregnado em todos seus mecanismos, valores, crenças, procedimentos e comportamentos.

A cultura organizacional e as estratégias de negócio e de uso de TI formam, juntamente com o estágio e a forma de utilização de TI na organização, os pontos mais relevantes do "cenário" em que o SI será implementado. Pode-se utilizar os estágios de crescimento de processamento de dados de Nolan ${ }^{7}$ para estudar uma organização e sua utilização de TI. Os estágios são: iniciação, contágio, controle, integração, administração de dados e maturidade, cabendo destacar a existência do ponto de transição entre os estágios de controle e integração, além de enfatizar os aspectos referentes à assimilação da TI pelos usuários e sua participação em seus processos.

Outras referências para estudar e compreender a TI numa organização incluem a Era do Computador e a Era da Informação de Synnott ${ }^{8}$, que definem a evolução da utilização de TI sob vários aspectos. Na Era do Computador, o enfoque era a produtividade e o controle; a competência principal era a técnica; o investimento, conservador e o principal componente era o computador. Na Era da Informação, o enfoque passou a ser a vantagem competitiva; as competências principais são, no negócio, aspectos gerenciais e estratégias de TI; $o$ investimento passou a ser agressivo e o componente principal passou a ser a informação e sua comunicação.

O Marketing Mix de Produto de TI, definido por Cash, McFarlan e McKenney", apresenta a evolução dos produtos requeridos de TI. O enfoque do futuro está em produtos pequenos e pouco ou nãoestruturados, integração ou agrupamento das tecnologias existentes e novas e obtenção de benefícios intangíveis. O enfoque do futuro, que está sendo confirmado na prática, exige mudanças na forma em que a utilização de TI é administrada.

Os ambientes de TI definidos por McFarlan, McKenney e Pyburn ${ }^{10}$ são suporte, reviravolta, fábrica e estratégico. $\mathrm{O}$ ambiente é definido pelos impactos da funcionalidade das atividades de TI e da carteira de aplicações em desenvolvimento nos negócios da empresa. Se os impactos são baixos, o ambiente é de suporte; se o impacto da carteira é alto e o da funcionalidade é baixo, o ambiente é de reviravolta; se o impacto da carteira é baixo e o da funcionalidade é alto, o ambiente é de fábrica; e, finalmente, se os impactos são altos nas duas dimensões, o ambiente é estratégico. A administração da utilização de TI deve ser aderente ao seu ambiente na organização.

A computadorização, segundo Kling ${ }^{11}$, é uma intervenção social e técnica comple$\mathrm{xa}, \mathrm{o}$ que torna os produtos baseados em computador (CBP) complexos social e tecnicamente, sendo que alterações substanciais de CBP na vida das organizações afeta as situações existentes e permite a alguns participantes alterarem os relacionamentos sociais. Os modelos WEB, propostos por Kling ${ }^{12}$, definem um contexto social para CBP como sendo as relações sociais entre um conjunto de participantes que podem influenciar a adoção, desenvolvimento ou o uso de tecnologia baseada em computador. Porém, a despeito da importância, segundo Hirschheim ${ }^{13}$, nosso enten-

\section{A implementação de um SI deve estar de acordo com a estratégia de uso da Tecnologia de Informação da organização, e esta, por sua vez, deve ser coerente com a sua estratégia de negócio.}

dimento coletivo dos impactos sociais de TI - sendo automação de escritório ou outro - é altamente deficiente. Portanto, é necessário estudar e entender os papéis e posturas dos atores de todo o ambiente organizacional para aumentar as chances de sucesso na implementação de um SI.
7. NOLAN, R. L. Managing the crises in data processing. Harvard Business Review, v. 57, n. 2, Mar./Apr. 1979.

8. SYNNOTT, W. R. The Information Weapon. New York: John Wiley, 1987.

9. CASH Jr., J. I., MCFARLAN, F. W. E McKENNEY, J. L. Corporate Information Systems Management: the issues facing senior executives. $3^{\text {a }}$ ed. Homewood: Richard D. Irwin, 1992.

10. MCFARLAN, E. W. MCKENNEY, J. L. e PYBURN, P. The Information Archipelago: plotting a course. Harvard Business Review, v. 61, n. 1, Jan./Feb. 1983.

11. KLING, R. Computado rization as an ongoing social and political process. Irvine University of California, 1985.

12. KLING, R. Defining the boundaries of Computing across complex organizations. No: BOLAND Jr., R. J. e HIRSCHHEIM, R. A. (org.), Critical issues in information systems research. New York: John Wiley, 1987.

13. HIRSCHHEIM, R. A. The effects of a priori views on the social implications of computing: the case of office automation. Computing Surveys, v. 18, n. 2, June 1986. 
14. BUDAN, R. The strategic use of information: seizing the competitve edge. Strategic Systems, Information Week, May 26, 1986.

15. SCHEIN, E. H. The role of the CEO in the management of change: the case of Information Technology. Massachusetts: MIT, Sloan School of Management, Working Paper, 1989.

16. BENJAMIN, R. I., ROCKART, J. F. E MORTON, M. S. $S$. Information Technology: a strategic opportunity. Sloan Management Review, v. 25, $\mathrm{n}$. 3, Spring 1984.

17. PARSONS, G. L. Information Technology: a new competitive weapon. Sloan Management Review, v. $25, n .1$, Fall 1983.

18. ALBERTIN, A. L. Administração de informática: funções e fatores criticos de sucesso. Sāo Paulo: Atlas, 1996.

19. EIN-DOR, P. e SEGEV, E. Strategic planning for management information systems. Management Science, v. 24, n. 15, November 1978

20. YIN, R. K. Case study research: desing and methods. Newburry Park: Sage Pubłications, 1989.
Alguns destes atores podem, por vários motivos, criar barreiras contra a implementação de um SI. Estas barreiras não são superadas simplesmente pela imposição; requerendo um planejamento completo, que considere explicações sobre os projetos organizacionais, de TI ou não, desmistificação e divulgação de tecnologia, convencimento de necessidade e envolvimento nas atividades.

Budan $^{14}$ define que existe uma relação direta entre o nível de sucesso de uma estratégia de TI e o nível de apoio da alta gerência a um desenvolvimento criativo de SI. Esta relação é devido à força influenciadora destes atores perante os demais participantes e seu papel de patrocinador e protetor do projeto. Segundo Schein ${ }^{15}$, devido à complexidade do meio organizacional e das forças atuantes, o chief executive officer (CEO) é chamado a ser uma força integradora, podendo assumir algumas das seguintes atitudes: céticos, dependentes, envolvidos e positivos.

Benjamin, Rockart e Morton ${ }^{16}$ argumentam que a atitude do CEO é requerida para que se considere a nova tecnologia como parte central do pensamento do negócio, e para que se examine como uma decisãochave da alta gerência pode ser afetada pela nova tecnologia. Em relação à utilização de TI no negócio, Parsons ${ }^{17}$ cita o depoimento de um presidente de divisão de uma grande corporação industrial: " $E u$ penso que a TI contribui em pelo menos 3\% para nosso lucro marginal final; porém, operacionalmente, nós não poderíamos passar uma semana sem o suporte de sistemas, e no mercado, eu não acredito que nós pudéssemos manter nossa participação sem tecnologia".

Concluindo, com a consideração da utilização de TI como um dos fatores críticos para o sucesso de uma organização, é necessário, segundo Albertin ${ }^{18}$, garantir o sucesso da própria área de Informática ou TI, através da implementação de SI bemsucedida, entre outros aspectos. Para tanto, é necessário ter:

- estratégia para ganhar um impulso competitivo através de TI;

- SI a ser implementado, que tenha características que garantam este impulso e tenha sido bem desenvolvido;
- bom conhecimento do cenário em que ele será desenvolvido e implementado;

- bom conhecimento dos atores participantes do processo e da organização;

- planejamento da intervenção, que considere todos estes aspectos na elaboração de uma estratégia de intervenção organizacional, a preparação do ambiente, a superação das barreiras para maximizar as chances de sucesso na implementação de um SI e garantir sua futura utilização.

No entanto, deve ser lembrado que o sucesso de um SI é medido, entre outras formas, pelo seu uso, segundo definição de Ein-dor e Segev ${ }^{19}$.

O estudo, aqui apresentado, buscou identificar a presença de variáveis do processo de desenvolvimento e implementação de SI dentro de três categorias - cenário, atores e planejamento da intervenção - e a forma pela qual elas devem ser estudadas e tratadas.

$\mathrm{Na}$ categorização das variáveis em cenário e atores, deve ser enfatizada a dinâmica existente entre suas variáveis, uma vez que os atores interferem diretamente no cenário e este, por sua vez, influencia os papéis dos atores.

O quadro 1 apresenta as categorias das variáveis do processo de desenvolvimento e implementação de SI.

Quadro 1 - Categoria das variávies

Cenário

Atores

Planejamento da intervenção

\section{IDENTIFICAÇÃO DAS VARIÁVEIS POR MEIO DE ESTUDO DE CASO}

A identificação das variáveis foi realizada por meio de estudo de múltiplos casos. O cuidado com a metodologia de estudo, baseada nas definições de Yin ${ }^{20}$, visou garantir a identificação das variáveis segundo critérios científicos e possibilitar a sua generalização. 
A análise dos casos é descrita neste artigo com o objetivo de contribuir para um melhor entendimento, tanto das variáveis como do ambiente organizacional e de utilização de SI em que elas foram identificadas e estudadas.

\section{Os casos estudados}

Os casos não serão aqui apresentados individualmente, nem as organizações serão identificadas por critérios de sigilo e estratégias. A análise dos casos foi feita com o enfoque das variáveis de cenário, atores e planejamento da intervenção, em projetos de SI integrados horizontal e verticalmente, na sua maioria interorganizacionais e envolvendo significativamente as organizações como um todo. As organizações que participaram do estudo pertencem a vários segmentos:

Setor de serviço: três organizações, sendo uma com administração do tipo associação/cooperativa:

- Organização S1:

- O processo de identificação de oportunidade de utilização de TI e preparação do ambiente teve a duração de sete anos;

- OSI mudou significativamente os processos de negócio.

- Organização S2:

- O processo de identificação de oportunidade de utilização de TI e preparação do ambiente contou com a participação de terceiros e foi imediata;

- OSI mudou completamente os processos de negócio.

- Organização S3:

- O processo de identificação de oportunidade de utilização de TI e preparação do ambiente contou com a participação de terceiros;

- O SI, que mudaria significativamente os processos de negócio, não foi efetivamente desenvolvido por falta de condições ambientais, identificada através das variáveis.

\section{Setor bancário: uma organização:}

- Organização B1:

- O processo de identificação de oportunidade de utilização de TI e preparação do ambiente contou com a participação de terceiros e foi imediata;

\author{
Existe uma relação direta \\ entre o nível de sucesso de \\ uma estratégia de $\mathrm{Tl}$ e $\mathrm{O}$ \\ nível de apoio da alta \\ gerência a um \\ desenvolvimento criativo \\ de SI.
}

- OSI atendeu principalmente as necessidades de informações gerências.

Setor industrial: uma organização.

- Organização I1:

- O processo de identificação de oportunidade e de utilização de TI e preparação do ambiente contou com a participação de terceiros e teve duração de dois anos;

- O projeto foi dividido em duas fases, a primeira voltada para uma área funcional específica e utilizada como preparação para a segunda fase, a qual mudou significativamente os processos de negócio.

O estudo confirmou a presença das mesmas variáveis em todos os projetos de desenvolvimento, implementação e uso de SI, além de seus estudos e compreensão serem determinantes para garantir o sucesso destes. O estudo ressalta, ainda, que os projetos de SI são projetos de mudança organizacional e esta intervenção deve ser planejada.

Particularmente, no caso da S3, o nãodesenvolvimento efetivo do SI deveu-se a não perfeita adequação entre as variáveis.

\section{Cenário}

As organizações, nos últimos anos, têm alimentado uma postura de modernização, onde a estratégia competitiva é consciente e sólida, sendo que a utilização de TI é encarada como essencial para esta estratégia de negócio. Esta postura permitiu que idéias inovadoras fossem tomando forma 
até tornarem-se realidade. Outro fato determinante em suas histórias foi que a área de Informática construiu um histórico de competência por meio de bons serviços e respeito a seus planos, que serviu para que esta ganhasse a confiança dos participantes das organizações.

Com base nesta história, a evolução da utilização de $\mathrm{TI}$ pode ser percebida pelo avanço dos estágios em que a organização se encontra. As organizações utilizaram formas de divulgação de tecnologia, entre elas a proliferação do uso de microcomputadores e terminais interativos.

O atual estágio das organizaç̃os pode ser definido como o de Integração, onde a área de Informática utiliza novas tecnologias, gerenciadores de bases de dados e nova estrutura organizacional. $O$ fato das organizações estarem neste estágio possibilitou que a idéia de implementação de

Cada implementação de um Sl em uma organização tem suas próprias características e deve ser estudado e planejado de acordo com a organização e seu momento.

SI's integrados, horizontal e verticalmente na organização, se tornasse realidade com todas as suas inovações. As tentativas ocorridas nos estágios anteriores encontraram dificuldades técnicas e sociais, mesmo com as organizações prepararando consistentemente a evolução dos estágios.

As organizações buscavam consolidar sua administração de TI com os aspectos da Era da Informação, por meio de produtos de TI com postura de futuro. Em algumas organizações, o ambiente de TI era de reviravolta; em outras, estratégico.

A estratégia de negócio das organizações, assim como as possibilidades de ganho de competitividade, por intermédio da utilização de TI, são bastante conhecidas pelos responsáveis pelas áreas e pelos participantes dos projetos de SI.
Os projetos de SI tinham seus orçamentos, e as alocações de recursos eram feitas pelo controle deste orçamento, onde qualquer solicitação era julgada mediante a justificativa direta da sua necessidade, requerendo decisões rápidas e de bom senso organizacional.

Os projetos eram de implementação de um sistema vital para o negócio da organização, pelo seu volume de transações e necessidade de rapidez, segurança $e$ conectividade com vários ambientes nacionais e internacionais. Este fato contribuiu para a percepção da importância dos projetos.

Os conflitos mais significativos eram de ordem política da alta gerência, a qual de certa forma protegia os projetos e as equipes dos efeitos destes conflitos. Os conflitos internos aos projetos eram tratados com os responsáveis pelas áreas envolvidas $\mathrm{e}$, se algum persistisse, a alta gerência interferia diretamente.

\section{Atores}

As equipes que desenvolveram os projetos, tanto usuários como as pessoas de Informática, capacitaram-se, tanto em nível de negócio como técnico, para melhor desenvolvê-los.

Algumas das capacitações necessárias para os projetos já existiam pela própria postura das áreas de propensão ao uso de tecnologia, desenvolvida ao longo da evolução da organização.

A continuidade dos projetos foi assegurada, entre outras coisas, pela união das equipes em torno dos projetos e com seus patrocinadores, bem como pelo apoio gerencial que eles tiveram na figura destes últimos, que sempre deixaram claro, para toda a organização, este apoio e a importância dos projetos para o negócio.

A área de Informática das organizaçōes está bastante próxima do nível mais alto da sua hierarquia decisória e o seu principal patrocinador, não só nos projetos em questão, é um dos principais executivos da organização, que detém poder suficiente para garantir a continuidade do projeto $e$ viabilizar recursos.

As principais decisões de direcionamento dos projetos foram tomadas pela alta gerência de cada organização; porém, a partir de certo ponto, a preocupação de 
promover o envolvimento de toda a organização esteve presente, mesmo que algumas das decisões mais relevantes já tivessem sido tomadas.

A postura dos usuários é de participação nos projetos e de formação de equipe, encarando-os como uma meta comum com a área de Informática. Os usuários dos projetos de SI eram internos, se considerarmos o seu solicitante e as áreas afetadas dentro da organização, e externos, se levarmos em conta que muitos projetos envolviam fornecedores, clientes ou parceiros externos das organizações. A visão destes dois tipos de usuários enfatiza o ambiente interorganizacional, com as particularidades de cada um dos envolvidos.

O bom relacionamento entre todos os responsáveis pelas áreas envolvidas e a participação efetiva da alta gerência contribuiu significativamente para que os projetos fossem considerados como um objetivo comum e tivessem sucesso.

\section{Planejamento da intervenção}

A preocupação de envolvimento tinha como base a identificação e superação das possíveis barreiras geradas por aqueles que teriam seus trabalhos afetados pela implementação dos SI's. Esta preocupação incluiu esclarecimentos sobre como seriam tratados cada um dos impactos sociais e técnicos dos envolvidos.

As pessoas que compunham a coordenação dos projetos eram boas conhecedoras da cultura das organizações envolvidas, tendo familiaridade com suas características políticas e sociais. Este conhecimento foi aplicado no estabelecimento da estratégia de intervenção que seria utilizada, bem como no seu planejamento. Muitas vezes, ele foi utilizado de forma inconsciente, dada a familiaridade proporcionada pela experiência acumulada ao longo dos anos nas organizações.

As equipes dos projetos conscientizaram-se, logo no início, de que a implementação do SI, com as características de integração horizontal e vertical, além de, em alguns casos, serem interorganizacionais, teria impactos sociais para os vários tipos de atores, que compõem as organizações envolvidas. Isto devido ao alto grau das mudanças nos processos e relacionamentos provadas pelos
SI's. O ambiente foi estudado principalmente para garantir que as possíveis barreiras tinham sido antecipadamente consideradas e que as medidas preventivas $e$ de superação seriam identificadas e tomadas.

Nas atividades de preparação do ambiente, social e técnico, para a implementação dos SI's, duas características foram mais marcantes: a de esclarecimento e a de envolvimento. Ambas se utilizaram basicamente das atividades de treinamento, reuniões, encontros formais e informais, e publicações.

O esclarecimento e o envolvimento foram largamente empregados para a superação de determinadas barreiras e prevenção de outras, e com esta atitude procurou-se garantir a futura aceitação e utilização dos SI. Este enfoque abrangeu tanto o âmbito interno como externo às organizações.

\section{CONTRIBUIÇÕES PARA A PRÁTICA DE IMPLEMENTAÇÃOO DE SI}

Cada implementação de um SI em uma organização tem suas próprias características e deve ser estudado e planejado de acordo com a organização e seu momento. Ou seja, não é possível agir da mesma maneira e executar as atividades exatamente iguais de uma implementação para outra. Isto negaria o princípio de projeto referente a não-repetitividade. Porém, é possível descrever as variáveis que devem ser consideradas e estudadas no processo de desenvolvimento e implementação de um SI, ou ainda na elaboração de cenários alternativos no processo de planejamento de TI.

\section{As variáveis assumem importância e criticidade diferentes dependendo do ambiente organizacional e tecnológico, e dos seus valores nestes ambientes.}




\section{Variáveis do cenário}

História da organização: a propensão à utilização de TI é construída ao longo da história da organização; sendo um reflexo de sua postura perante novos desafios tecnológicos, podendo ainda ser entendida através dos estágios de utilização de TI da organização, os produtos de TI, os ambientes de TI, entre outras teorias. Para aumentar as chances de sucesso na implementação de um SI, a organização precisa ser preparada, devendo-se esperar o momento certo.

Estratégias de negócio: a organização precisa saber onde quer chegar e como o fará, para poder atribuir suas prioridades e decidir, entre outras coisas, que SI's serão importantes para isto. Por outro lado, a área de Informática, ou TI, precisa entender de tecnologia e do negócio da organização para poder sugerir sua aplicabilidade, tanto para a operacionalização como para a estratégia competitiva da organização. Assim como a alta gerência e demais áreas organizacionais precisam ter conhecimento de TI para entender e aproveitar a sua potencialidade.

Recursos: a TI de uma organização pode ser considerada um investimento que requer certa quantidade de recursos, sejam financeiros, humanos, materiais etc. Sendo impossível utilizá-la sem a disponibilidade adequada destes recursos. Porém, é necessário que esta disponibilidade seja controlada e sua necessidade comprovada por meio de benefícios organizacionais, tangíveis ou intangíveis.

Importância do projeto: o SI a ser implementado deve ser entendido como importante para a organização, seja na sua operacionalização ou na sua estratégia competitiva. É muito difícil ter sucesso na implementação de um SI que a organização não considera e percebe como importante ou necessário.

Conflitos: os conflitos existentes na organização devem ser entendidos e, sempre que possível, eliminados. Os SI's, desenvolvidos e implementados em am- bientes com muitos conflitos, refleti-los-á.

O quadro 2 apresenta as variáveis identificadas na categoria de cenário.

\begin{tabular}{|l|l|}
\hline \multicolumn{2}{|c|}{ Quadro 2 - Variáveis de cenário } \\
\hline \multirow{3}{*}{ Cenário } & História da organização \\
& Estratégias de negócio \\
& Importância do projeto \\
& Conflitos \\
& Recursos \\
\hline
\end{tabular}

\section{Variáveis dos atores}

Capacitação: os membros das equipes envolvidas no desenvolvimento e implementação de um SI devem ter uma capacitação funcional e técnica compatível com as características do SI e das necessidades da organização, ou terem um plano para adquiri-la em tempo adequado.

Equipe: as equipes devem ser unidas internamente e entre elas para que trabalhem coesas e em acordo com o objetivo comum, o SI. Esta união também deve existir entre o patrocinador $e$ as equipes.

Usuários: a cultura e a experiência de utilização de TI dos usuários deve ser compatível com o SI a ser implementado, bem como com a própria área de TI e viceversa.

Apoio da alta gerência: um projeto de SI, que não tenha o apoio de um executivo da organização com poder suficiente para garantir sua continuidade e os recursos necessários, terá grande chance de fracasso. Além do apoio em relação ao poder, a alta gerência deve deixar claro sua convicção da importância do projeto para a estratégia do negócio por meio de suas atitudes.

Patrocinador: deve haver um executivo que tenha o papel de patrocinador do projeto do SI, que com sua atitude demonstre a importância do projeto e do próprio SI, garanta sua continuidade com a alta gerência e decida as possíveis diferenças entre os participantes do projeto. 
O quadro 3 apresenta as variáveis identificadas na categoria de atores.

\begin{tabular}{|l|l|}
\hline Quadro 3 - Variáveis de atores \\
\hline Atores & Apoio da alta gerência \\
& Patrocinador \\
& Equipe \\
& Usuários \\
& Capacitação \\
\hline
\end{tabular}

Variáveis do planejamento da intervenção

Impactos sociais: todas as implementações de SI afetam o ambiente social da organização e o modo de trabalhar de seus participantes. Estes impactos devem ser previstos, estudados e trabalhados por meio de esclarecimentos, envolvimento, eliminação de dúvidas e medos, facilitadores de mudanças etc.

Estratégia de intervenção: com base no conhecimento da organização e dos impactos futuros, deve-se formular as estratégias de intervenção e proceder seu planejamento.

Prevenção: deve-se estudar a organização e os impactos para elaborar as atividades necessárias para prevenir as possíveis barreiras e vencer as inevitáveis.

Esclarecimento e envolvimento: toda a organização deve saber a importância do projeto e do próprio SI, ter conhecimento de suas informações relevantes e ser envolvida no esforço comum. Isto pode ser conseguido por intermédio de treinamento, reuniões, encontros formais ou informais, entre outras estratégias.

Disseminação e desmistificação de TI: todo o planejamento de intervenção feito para a implementação de um SI deve considerar a disseminação da cultura de TI, bem como a sua desmistificação, para garantir um bom entendimento e a eliminação, por exemplo, de possível medo de algo desconhecido ou falta de segurança em relação à própria tecnologia.

O quadro 4 apresenta as variáveis identificadas na categoria de planejamento da intervenção.

\section{Quadro 4 - Variáveis de planejamento da intervenção}

Planejamento da intervenção

Impactos socias

Estratégia de intervenção

Prevenção

Esclarecimento e envolvimento

Disseminação e desmistificação

\section{CONCLUSÃo}

As variáveis do processo de desenvolvimento e implementação de SI se mostraram significativamente úteis para o estudo e a melhoria do conhecimento sobre este processo, bem como para sua administração.

As variáveis têm sido estudadas e confirmadas continuamente, tanto nos trabalhos de pesquisa como de consultoria empresarial. Nos casos de sucesso de desenvolvimento e implementação de SI, notase a coerência entre os valores das variáveis e sua aplicação para a identificação das dimensões a serem tratadas visando a busca desta coerência.

As variáveis assumem importância e criticidade diferentes dependendo do ambiente organizacional e tecnológico, e dos seus valores nestes ambientes, porém sempre existem e o grau de inter-relação entre as variáveis é muito elevado.

$\mathrm{O}$ quadro 5 apresenta as variáveis identificadas, distribuídas nas categorias.

\section{Quadro 5 - Variáveis do processo de desenvolvimento e implentação de SI}

\begin{tabular}{|l|l|}
\hline Cenário & $\begin{array}{l}\text { História da organização } \\
\text { Estratégias de negócio } \\
\text { Importância do projeto } \\
\text { Conflitos } \\
\text { Recursos }\end{array}$ \\
\hline Atores & $\begin{array}{l}\text { Apoio da alta gerência } \\
\text { Patrocinador } \\
\text { Equipe } \\
\text { Usuários } \\
\text { Capacitação }\end{array}$ \\
\hline Planejamento da \\
Intervenção & $\begin{array}{l}\text { Impactos sociais } \\
\text { Estratégia de intervenção } \\
\text { Prevenção } \\
\text { Esclarecimento e envolvimento } \\
\text { Disseminação e desmistificação }\end{array}$ \\
\hline
\end{tabular}

